\title{
Observation of Atherosclerotic Plaque Phantoms through Saline or Blood Layers by Near-Infrared Hyperspectral Imaging
}

\author{
Katsunori Ishii ${ }^{1}$, Akiko Kitayabu ${ }^{1}$, Ryo Nagao', Kunio Awazu ${ }^{1,2,3^{*}}$ \\ ${ }^{1}$ Medical Beam Physics Laboratory, Graduate School of Engineering, Osaka University, Osaka, Japan \\ ${ }^{2}$ Graduate School of Frontier Biosciences, Osaka University, Osaka, Japan \\ ${ }^{3}$ The Center for Advanced Medical Engineering and Informatics, Osaka University, Osaka, Japan \\ Email: *awazu@see.eng.osaka-u.ac.jp
}

Received 11 August 2014; revised 8 September 2014; accepted 2 October 2014

Copyright (C) 2014 by authors and Scientific Research Publishing Inc.

This work is licensed under the Creative Commons Attribution International License (CC BY).

http://creativecommons.org/licenses/by/4.0/

(c) (i) Open Access

\begin{abstract}
We observed atherosclerotic plaque phantoms using a novel near-infrared (NIR) hyperspectral imaging (HSI) technique. Data were obtained through saline or blood layers to simulate an angioscopic environment for the phantom. For the study, we developed a NIR-HSI system with an NIR supercontinuum light source and mercury-cadmium-telluride camera. Apparent spectral absorbance was obtained at wavelengths of $1150-2400 \mathrm{~nm}$. Hyperspectral images of lipid were constructed using a spectral angle mapper algorithm. Bovine fat covered with saline or blood was observed using hyperspectral images at a wavelength around $1200 \mathrm{~nm}$. Our results show that NIR-HSI is a promising angioscopic technique with the potential to identify lipid-rich plaques without clamping and saline injection.
\end{abstract}

\section{Keywords}

Hyperspectral Imaging, Near-Infrared Range, Atherosclerotic Plaque, Angioscopy

\section{Introduction}

Atherosclerosis is a disease in which plaque builds up inside the arterial wall. Many acute ischemic events result from the rupture of asymptomatic vulnerable plaques, which can cause thrombotic occlusion and myocardial infarction. Identification of potentially lethal plaques before such disruption will facilitate the development of therapeutic strategies for preventing these events [1]. The most common modalities are currently applied for clini-

"Corresponding author.

How to cite this paper: Ishii, K., Kitayabu, A., Nagao, R. and Awazu, K. (2014) Observation of Atherosclerotic Plaque Phantoms through Saline or Blood Layers by Near-Infrared Hyperspectral Imaging. Optics and Photonics Journal, 4, 271-279.

http://dx.doi.org/10.4236/opj.2014.410026 
cal intravascular diagnostic imaging of atherosclerotic plaque [2] [3] including intravascular ultrasound (IVUS) [4], optical coherence tomography (OCT) [5], photoacoustic tomography [6], angioscopy [7], and combination of these methods [8] [9]. Spectroscopic techniques are also being applied, based on advances in spectroscopic photoacoustic imaging [10], fluorescence spectroscopy [11], Raman spectroscopy [12], and near-infrared (NIR) spectroscopy [13] [14]. Such methods can provide chemical information about the artery and plaque.

Hyperspectral imaging (HSI) [15] is a spectroscopic imaging method that combines chemical specificity with spatial resolution. This technique can detect the presence of lipid-rich plaques. Previous work demonstrated the applicability of HSI to detection of atherosclerotic plaques in the visible range [16]. Hemoglobin in blood strongly absorbs visible light. This necessitates the use of a saline flush to deliver sufficient light to the vessel wall if HSI is implemented in vivo using an intravascular probe in a manner analogous to IVUS or OCT.

NIR light efficiently penetrates biological tissues, and the NIR region contains the characteristic absorption range of lipid-rich plaques [13] [17]. Thus, NIR spectroscopy in the wavelength range of $1000-2500 \mathrm{~nm}$ is being evaluated as a potential tool for identifying lipid-rich plaques [10]-[14] [17] [18]. In addition, the absorption of NIR by blood is low, and is dominated by water rather than hemoglobin, potentially obviating the need for a saline flush in an intravascular implementation. Consequently, NIR spectroscopy may enable lipid-rich plaques to be imaged in the presence of blood [18].

The objective of this study was to evaluate the potential of NIR-HSI for imaging of lipid-rich plaques through saline or blood in an in vivo environment. We demonstrated that NIR-HSI could detect and distinguish lipids in a biological tissue model of atherosclerotic phantoms. We also determined the optimal effective NIR range for imaging of lipids through blood or saline.

\section{Materials and Methods}

\subsection{Exposed Plaque Phantom}

An atherosclerotic phantom was prepared using a biological tissue model, bovine fat, and saline or heparinized porcine blood. The biological tissue model (tissue-mimic model) consisted of $0.5 \mathrm{mg} / \mathrm{mL}$ hemoglobin (H737910G, Sigma-Aldrich, USA), $0.1 \mathrm{~g} / \mathrm{mL}$ gelatin (G2500-500G, Sigma-Aldrich, USA), and 2\% Intralipid (FB01IL20, Terumo, Japan) [19]. Bovine fat was used as a model for lipid-rich plaques in wavelength bands around 1200, 1700, and $2300 \mathrm{~nm}$. Figure 1(a) shows a schematic illustration of an exposed plaque phantom. A 1-mm layer of bovine fat was set at the center of the biological tissue model. Before measurement, a 0 - 10-mm thick layer of saline or a 0 - 2-mm thick layer of blood was overlaid on the sample.

\subsection{Vulnerable Plaque Phantom}

Vulnerable plaques are usually characterized by a thin fibrous cap overlaying a soft lipid pool. The thickness of the thin fibrous caps is under $65 \mu \mathrm{m}$, whereas that of the soft lipid pool is nearly $800 \mu \mathrm{m}$ [20]. As shown in Figure 1(b), a vulnerable plaque phantom was prepared with a 0.1-mm thick biological tissue model overlaying the exposed plaque phantom. Then, a 0 - 4-mm thick layer of saline or blood was overlaid on the sample.

\subsection{NIR-HSI Set Up}

Figure 2 shows a schematic diagram of the NIR-HSI system. Supercontinuum (SC) light (prototype, Sumitomo Electric Industries, Japan) was used as a light source. The wavelength range and maximum average power were $1100-2400 \mathrm{~nm}$ and $\sim 40 \mathrm{~mW}$, respectively. Samples were irradiated with light that was wavelength-selected light using a monochromator (SPG-120IR, Shimadzu, Japan). The diffuse reflected light on the sample was detected by a mercury-cadmium-telluride (MCT) camera that collected images of $320 \times 256$ pixels (XEVA-2.5, Xenics, Belgium).

\subsection{Data Acquisition}

Spectral absorption values were obtained at wavelengths of 1150 - 1240, $1700-1900$, and $2300-2400 \mathrm{~nm}$ at 10 -nm intervals. The groups of hyperspectral data (called hyperspectral cubes) collected at those wavelengths consisted of 10, 21, and 11 images, respectively. Hyperspectral data were calibrated using black-and-white images. The white image cube was obtained from a diffuse reflection standard (WS-1, Ocean Optics, USA). The corresponding image cube was acquired under conditions identical to those for the measurement sample. The 


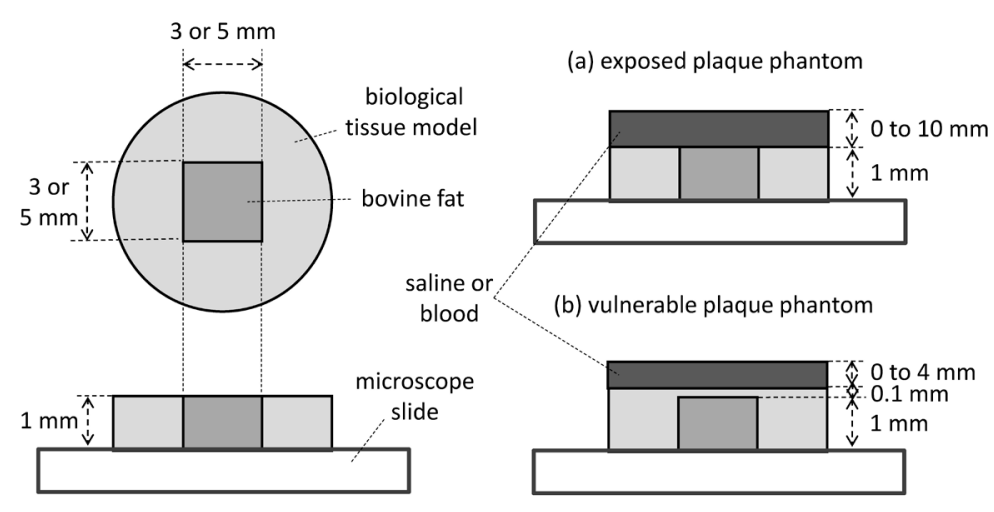

Figure 1. Schematic view of measurement samples. Image (a) is a cross-section view of an exposed plaque phantom; Image (b) is a cross-section view of a vulnerable plaque phantom.

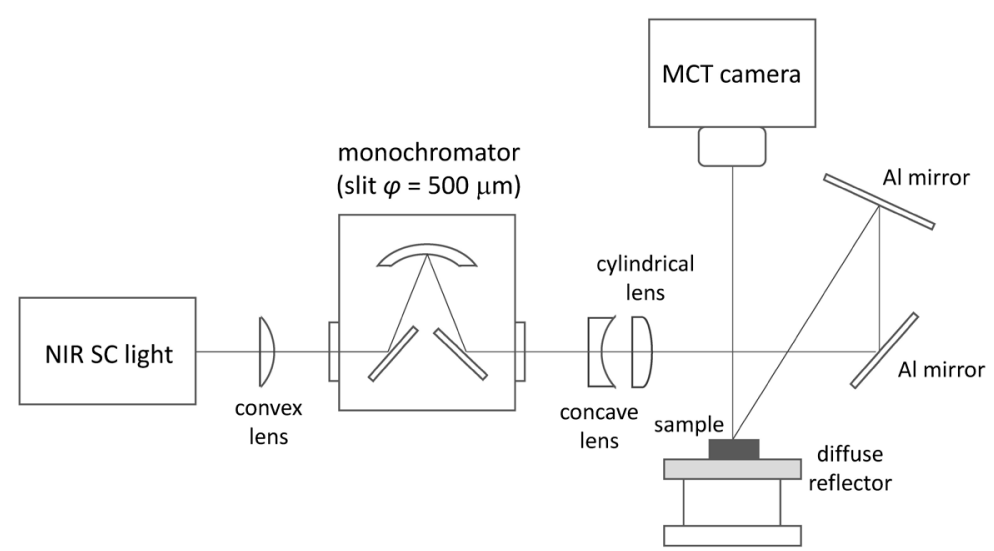

Figure 2. Schematic diagram illustrating the NIR-HSI system.

black images were obtained with the light source off to prevent any light from penetrating into the camera and were used to estimate the dark current noise. The reflectance factor $R_{i j}(\lambda)$ at wavelength $\lambda$ and the spatial coordinates $(i, j)$ were calculated using the following equation:

$$
R_{i j}(\lambda)=\frac{I_{i j}(\lambda)-D_{i j}}{W_{i j}(\lambda)-D_{i j}}
$$

where $I_{i j}(\lambda)$ is the spectral reflectance of the sample captured by the MCT camera, $D_{i j}$ is the intensity of the black images, and $W_{i j}(\lambda)$ is the spectral intensity of the white images.

Finally, the so-called apparent absorbance at each pixel was calculated using the modified Beer-Lambert law [21].

$$
A_{i j}(\lambda)=-\log _{10}\left[R_{i j}(\lambda)\right]
$$

where $A_{i j}(\lambda)$ is the apparent absorbance of the measurement sample.

\subsection{Image Processing}

The spectral angle mapper algorithm (SAM) was used for imaging analysis [22]. SAM is a classification method that permits rapid mapping by calculating the spectral similarity between the imaging spectra and a reference spectrum. This method treats both spectra as vectors in $n$-dimensional space and calculates the spectral angle between them. Small angles means high similarity. This spectral angle is relatively insensitive to changes in pixel illumination because increasing or decreasing illumination does not change the direction of the vector.

In a hyperspectral cube, each pixel $(i, j)$ has each its own vector. The angle between each vectors can be cal- 
culated as follows:

$$
\cos \theta=\frac{|\vec{A} \cdot \vec{B}|}{|\vec{A}||\vec{B}|}
$$

where $A$ is a reference vector, $B$ is the vector of each pixel, and $\theta$ is the angle between $A$ and $B$. In order to obtain the hyperspectral image, the value of $\cos \theta$ is divided from 0 (black) to 255 (white), expressed as image values. The spectrum of bovine fat, which was measured by Fourier transform NIR spectroscopy (FT-NIR), was adopted as the reference vector [23].

\section{Results}

\subsection{Optimal Wavelength Band for Lipid Observation}

Figure 3 shows the hyperspectral images of the exposed plaque phantom through a 0.5 -mm thick layer of saline or blood. Bovine fat was observed through a saline layer at wavelengths of 1150 - 1240 (around 1200), 1700 1900 (around 1700), and 2300 - 2400 (around 2300) nm. The images around 1200 and $1700 \mathrm{~nm}$ were especially clear. Bovine fat was observed through the blood layer only in the wavelength band around $1200 \mathrm{~nm}$, but the image was blurry.

\subsection{Effect of the Thickness of the Saline or Blood Layer}

Figure 4 shows hyperspectral images of the exposed plaque phantoms through a 0 - 10-mm thick layer of saline

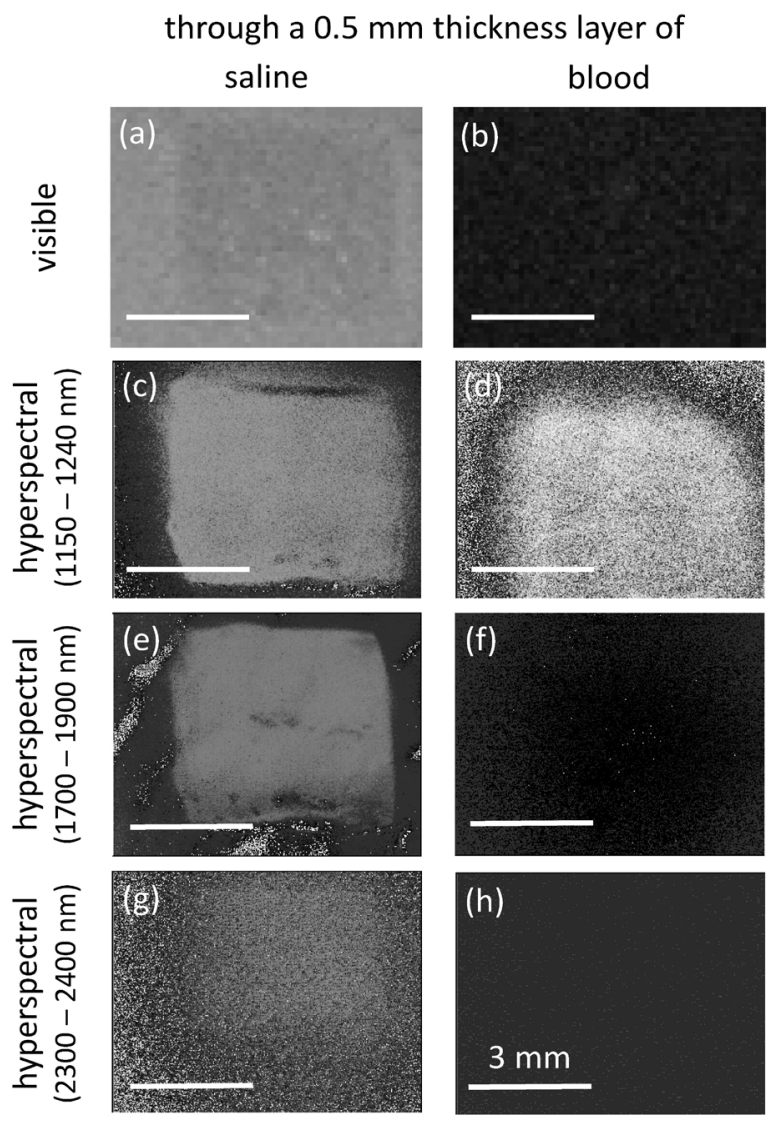

Figure 3. Images of exposed plaque phantoms taken through $0.5 \mathrm{~mm}$ saline (left) or blood (right). (a) and (b) are visible images; (c) and (d) are hyperspectral images at $1150-1240 \mathrm{~nm}$; (e) and (f) are hyperspectral images at $1700-1900 \mathrm{~nm}$; (g) and (h) are hyperspectral images at $2300-2400 \mathrm{~nm}$. 

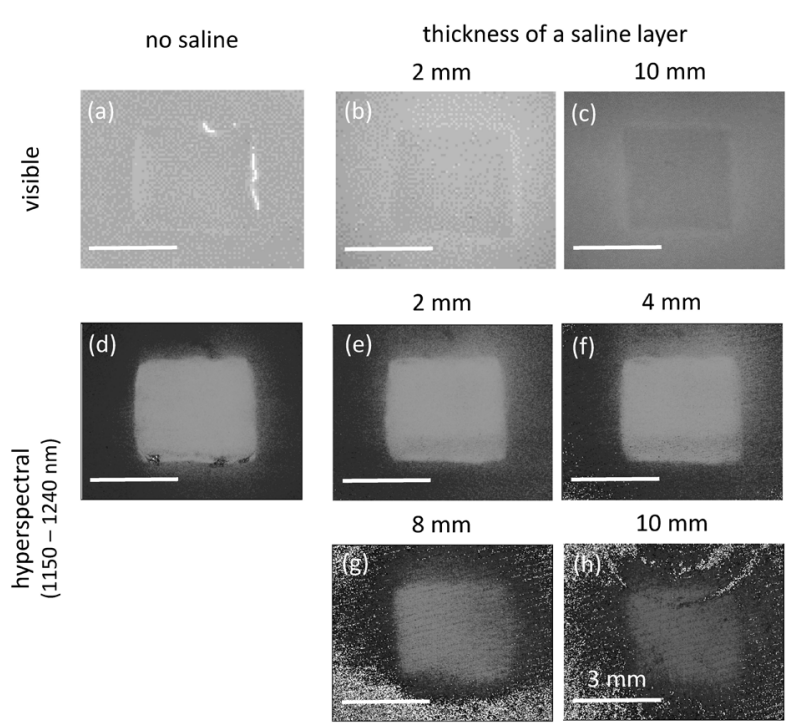

\begin{abstract}
Figure 4. Images of exposed plaque phantoms taken through saline. The three upper panels show visible images taken through saline layers with thicknesses of (a) $0 \mathrm{~mm}$; (b) $2 \mathrm{~mm}$; and (c) $10 \mathrm{~mm}$. The five lower panels show hyperspectral images taken at wavelengths around $1200 \mathrm{~nm}$ through saline layers with thicknesses of (d) $0 \mathrm{~mm}$; (e) $2 \mathrm{~mm}$; (f) $4 \mathrm{~mm}$; (g) $8 \mathrm{~mm}$; and (h) $10 \mathrm{~mm}$.
\end{abstract}

at wavelengths around $1200 \mathrm{~nm}$. Bovine fat was observed under all conditions, but images taken through saline layers over $8 \mathrm{~mm}$ thick exhibited weak blurring. Figure 5 shows hyperspectral images of the exposed plaque phantoms through a 0 - 2-mm thick layer of blood at wavelengths around $1200 \mathrm{~nm}$. Lipid could be observed clearly under a layer of blood with a thickness of $1.5 \mathrm{~mm}$ or less. Images of bovine fat through blood layers over $1.5 \mathrm{~mm}$ thick exhibited strong blurring, and images could not be collected at all through a blood layer more than $2 \mathrm{~mm}$ thick. The error rate of an image of bovine fat covered by a $0.5-\mathrm{mm}$ thick layer of blood was $6.2 \%$, whereas the error rate of an image covered by a $1.0-\mathrm{mm}$ thick layer of blood was $22.3 \%$.

Figure 6 shows the hyperspectral images of the vulnerable plaque phantoms through a 0 - 4-mm thick layer of saline with a wavelength around $1200 \mathrm{~nm}$. Bovine fat was observed under all conditions, but images collected through saline layers over $4 \mathrm{~mm}$ thick exhibited weak blurring. Figure 7 shows the hyperspectral images of the vulnerable plaque phantoms taken through a 0 - 4-mm thick layer of blood in the wavelength band around 1200 $\mathrm{nm}$. The lipid could be clearly observed when the blood layer was less than $1.0 \mathrm{~mm}$ thick, but images could not be collected when the blood layer was $4 \mathrm{~mm}$ thick. The error rate of an image of bovine fat covered by a $0.5-\mathrm{mm}$ thick layer of blood was $0.7 \%$, whereas the error rate of an image covered by a 1.0 -mm thick layer of blood was $7.7 \%$.

\title{
4. Discussion
}

Figure 8 shows absorption spectra of an atherosclerotic plaque and a normal artery, measured by FT-NIR [23]. The spectra were normalized at a wavelength of $1950 \mathrm{~nm}$. Atherosclerotic plaques have absorption bands around 1200, 1450, 1700, 2000, and $2300 \mathrm{~nm}$. The bands around 1200 and $1700 \mathrm{~nm}$ correspond to the second and first overtones of the $\mathrm{CH}$ stretching vibration mode, respectively. The band around $2300 \mathrm{~nm}$ corresponds to the second overtone of the $\mathrm{CH}$ deformation vibration mode. The band around $1450 \mathrm{~nm}$ corresponds to the first overtone of the $\mathrm{OH}$ stretching vibration mode. The band around $2000 \mathrm{~nm}$ corresponds to the combination tone of $\mathrm{OH}$ stretching and $\mathrm{OH}$ deformation vibration modes [24].

As shown in Figure 3, in exposed plaque phantoms covered by saline or blood, bovine fat could not be observed at wavelengths around $2300 \mathrm{~nm}$, because water has a strong absorption band at wavelengths over 1400 $\mathrm{nm}$. Through a blood layer, bovine fat could not be observed at wavelengths around $1700 \mathrm{~nm}$, because water in blood absorbs strongly in this range, and red blood cells strongly scatter light [25]. Figure 9 shows the optical penetration depth of blood. The spectrum was obtained by integrating sphere measurements in combination with an inverse Monte Carlo simulation [26]. As shown in Figure 9, the penetration depth was higher in the wave- 

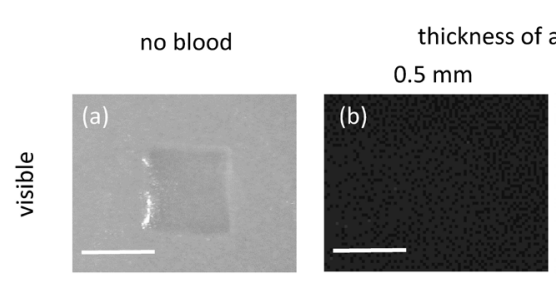

$0.5 \mathrm{~mm}$

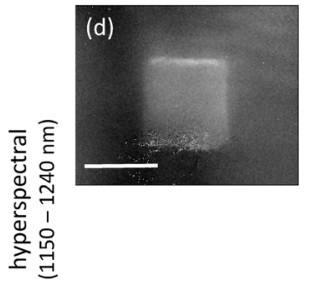

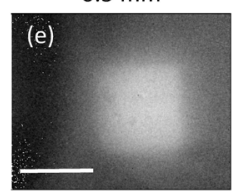

$1.5 \mathrm{~mm}$

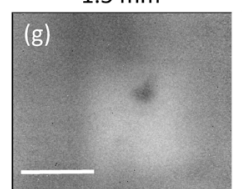

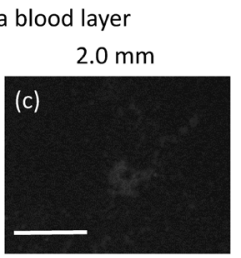

$1.0 \mathrm{~mm}$

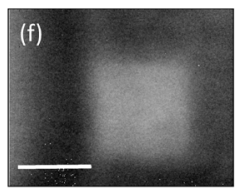

$2.0 \mathrm{~mm}$

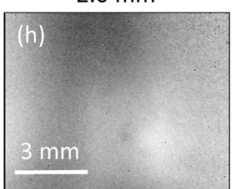

Figure 5. Images of exposed plaque phantoms taken through blood at wavelengths around $1200 \mathrm{~nm}$. The upper three panels show visible images taken through blood layers with thicknesses of (a) $0 \mathrm{~mm}$; (b) $0.5 \mathrm{~mm}$; and (c) 2.0 $\mathrm{mm}$. The five lower panels show hyperspectral images taken at wavelengths around $1200 \mathrm{~nm}$ through blood layers with thicknesses of (d) $0 \mathrm{~mm}$; (e) 0.5 mm; (f) $1.0 \mathrm{~mm}$; (g) $1.5 \mathrm{~mm}$; and (h) $2.0 \mathrm{~mm}$ blood layer.
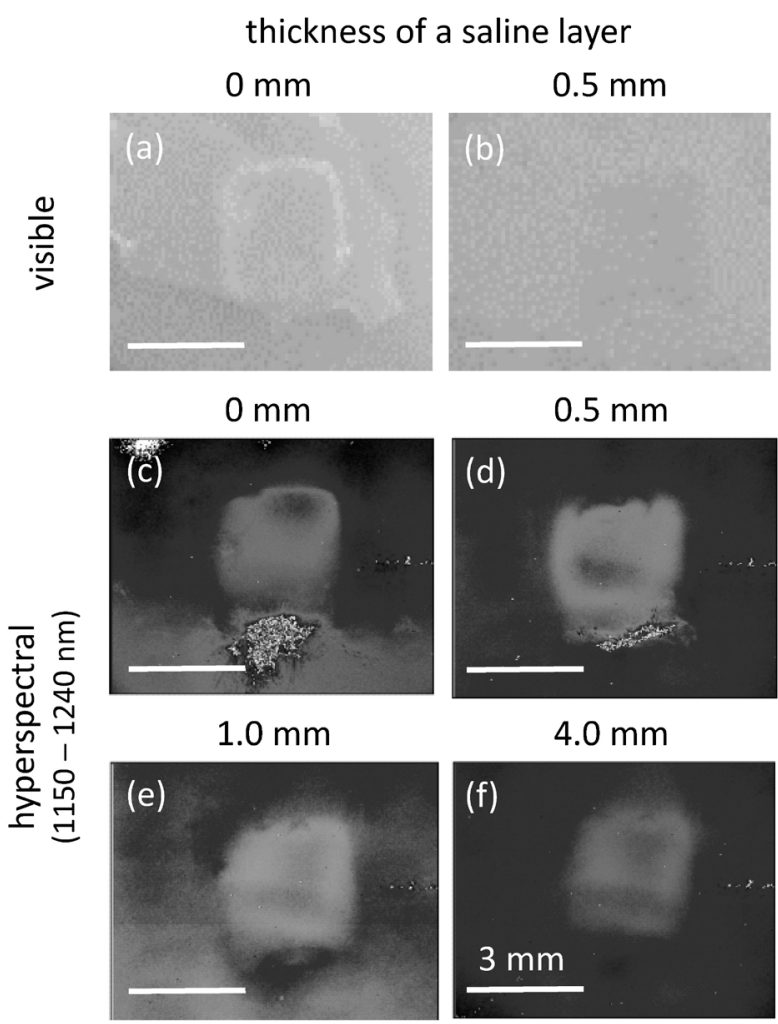

Figure 6. Images of vulnerable plaque phantoms taken through saline. The upper two panels show visible images taken through saline layers with thicknesses of (a) $0 \mathrm{~mm}$ and (b) $0.5 \mathrm{~mm}$. The lower four panels show hyperspectral images taken at wavelengths around $1200 \mathrm{~nm}$ through saline layers with thicknesses of (c) $0 \mathrm{~mm}$; (d) $0.5 \mathrm{~mm}$; (e) $1.0 \mathrm{~mm}$; and (f) $4.0 \mathrm{~mm}$. 


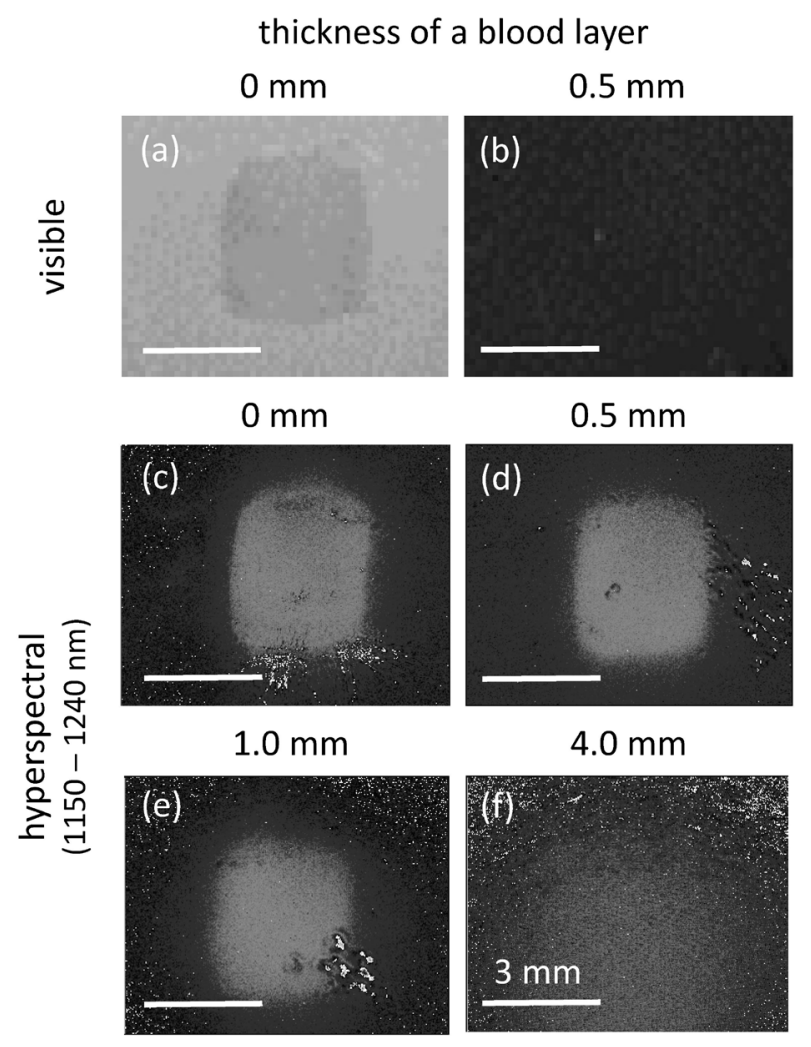

Figure 7. Images of vulnerable plaque phantoms taken through blood. The upper two panels show visible images taken through blood layers with thicknesses of (a) $0 \mathrm{~mm}$ and (b) $0.5 \mathrm{~mm}$. The lower four panels show hyperspectral images taken at wavelengths around $1200 \mathrm{~nm}$ through blood layers with thicknesses (c) $0 \mathrm{~mm}$; (d) $0.5 \mathrm{~mm}$; (e) $1.0 \mathrm{~mm}$; and (f) $4.0 \mathrm{~mm}$.

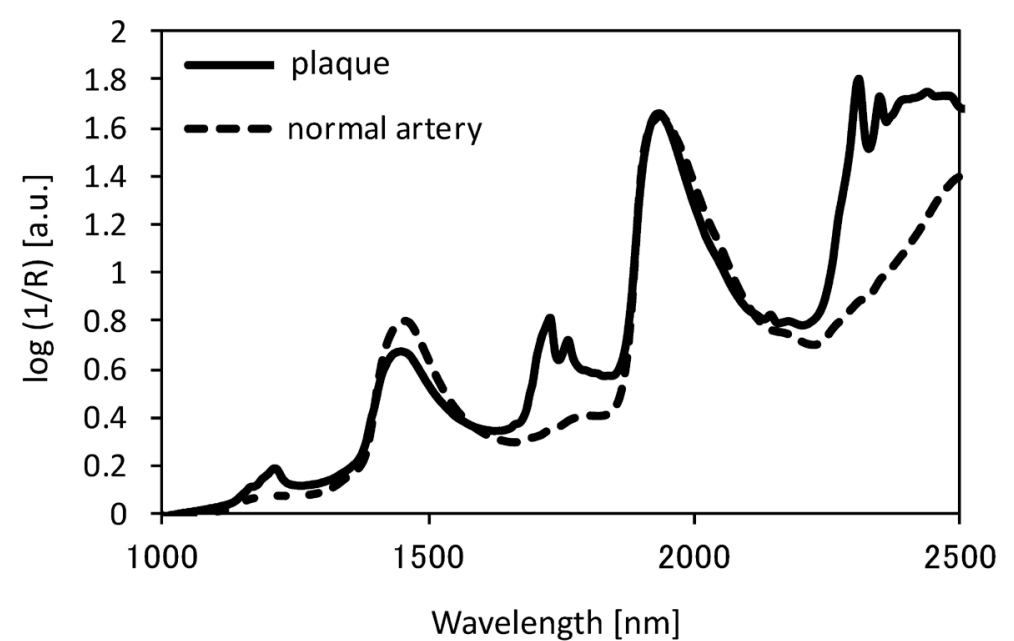

Figure 8. Absorption spectra of arterial tissues. Solid line, atherosclerotic plaque; dashed line, normal artery.

length band around $1200 \mathrm{~nm}$ than in the band around $1700 \mathrm{~nm}$. Thus, we considered the wavelength band around $1200 \mathrm{~nm}$ to be optimal for the observation of atherosclerotic plaques through saline and blood. However, as shown in Figure 5 and Figure 7, images collected through blood exhibited prominent and blurring at wavelength band around $1200 \mathrm{~nm}$. The blurred images were indistinct due to light scattering through the blood layer, 


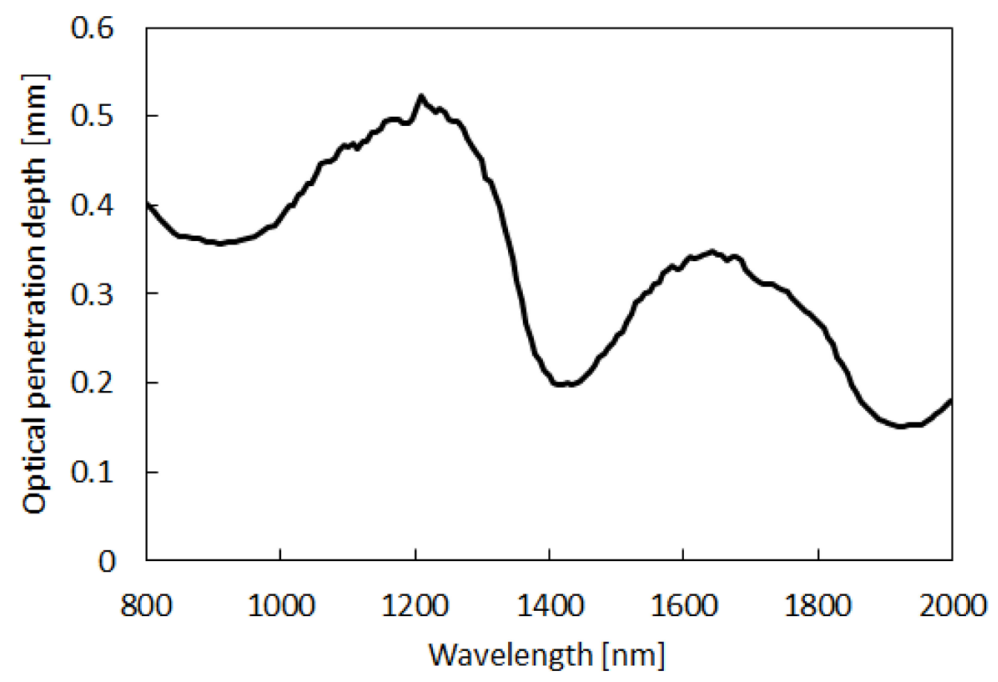

Figure 9. Optical penetration depth of blood.

making accurate detection of the atherosclerotic plaque difficult. To solve this problem, a scatter correction method is required.

NIR-HSI has the potential to be applied as an angioscopic technique for identifying lipid-rich plaques without clamping and saline injection. The minimum focus of an angioscope is about $1 \mathrm{~mm}$. These results support the idea that NIR-HSI at a wavelength band around $1200 \mathrm{~nm}$ could be used to detect lipid-rich plaques through saline or blood layers with an angioscope. However, because our measurement sample was an optical phantom, it will be necessary to perform future studies on actual human atherosclerotic plaques.

\section{Conclusion}

Atherosclerotic plaque phantoms were observed through saline or blood layers with the NIR-HSI system. In saline and blood environments, wavelengths around $1200 \mathrm{~nm}$ were optimal for lipid detection. Hyperspectral images collected through saline layers were clearer than those collected through blood layers in the phantoms of both types. NIR-HSI has the potential to be used in angioscopic diagnostic techniques aimed at identifying lipidrich plaques without clamping and saline injection.

\section{References}

[1] Fayad, Z.A. and Fuster, V. (2001) Clinical Imaging of the High-Risk or Vulnerable Atherosclerotic Plaque. Circulation Research, 89, 305-316. http://dx.doi.org/10.1161/hh1601.095596

[2] Honda, Y. and Fitzgerald, P.J. (2008) Frontiers in Intravascular Imaging Technologies. Circulation, 117, $2024-2037$. http://dx.doi.org/10.1161/CIRCULATIONAHA.105.551804

[3] Suter, M.J., Nadkarni, S.K., Weisz, G., Tanaka, A., Jaffer, F.A., Bouma, B.E. and Tearney, G.J. (2011) Intravascular Optical Imaging Technology for Investigating the Coronary Artery. JACC: Cardiovascular Imaging, 4, 1022-1039. http://dx.doi.org/10.1016/j.jcmg.2011.03.020

[4] Nissen, S.E. and Yock, P. (2001) Intravascular Ultrasound: Novel Pathophysiological Insights and Current Clinical Applications. Circulation, 103, 604-616. http://dx.doi.org/10.1161/01.CIR.103.4.604

[5] Tearney, G.J., Jang, I.K. and Bouma, B.E. (2006) Optical Coherence Tomography for Imaging the Vulnerable Plaque. Journal of Biomedical Optics, 11, Article ID: 021002. http://dx.doi.org/10.1117/1.2192697

[6] Jansen, K., van der Steen, A.F.W., Springeling, G., van Beusekom, H.M.M., Oosterhuis, J.W. and van Soest, G. (2011) Intravascular Photoacoustic Imaging of Human Coronary Atherosclerosis. Optics Letters, 36, 597-599. http://dx.doi.org/10.1364/OL.36.000597

[7] Uchida, Y. and Uchida, Y. (2012) Advances in Angioscopic Imaging of Vascular Disease. World Journal of Cardiovascular Surgery, 2, 114-131. http://dx.doi.org/10.4236/wjcs.2012.24021

[8] Yin, J., Yang, H.C., Li, X., Zhang, J., Zhou, Q., Hu, C., Shung, K.K. and Chen, Z. (2010) Integrated Intravascular Optical Coherence Tomography Ultrasound Imaging System. Journal of Biomedical Optics, 15, Article ID: 010512. 
http://dx.doi.org/10.1117/1.3308642

[9] Wang, B., Karpiouk, A., Yeager, D., Amirian, J., Litovsky, S., Smalling, R. and Emelianov, S. (2012) In Vivo Intravascular Ultrasound-Guided Photoacoustic Imaging of Lipid in Plaques Using an Animal Model of Atherosclerosis. Ultrasound in Medicine and Biology, 38, 2098-2103. http://dx.doi.org/10.1016/j.ultrasmedbio.2012.08.006

[10] Allen, T.J., Hall, A., Dhillon, A.P., Owen, J.S. and Beard, P.C. (2012) Spectroscopic Photoacoustic Imaging of LipidRich Plaques in the Human Aorta in the 740 to $1400 \mathrm{~nm}$ Wavelength Range. Journal of Biomedical Optics, 17, Article ID: 061209. http://dx.doi.org/10.1117/1.JBO.17.6.061209

[11] Zhu, B., Jaffer, F.A., Ntziachristos, V. and Weissleder, R. (2005) Development of a Near Infrared Fluorescence Catheter: Operating Characteristics and Feasibility for Atherosclerotic Plaque Detection. Journal of Physics D, 38, 27012707.

[12] Komachi, Y., Sato, H. and Tashiro, H. (2006) Intravascular Raman Spectroscopic Catheter for Molecular Diagnosis of Atherosclerotic Coronary Disease. Applied Optics, 45, 7938-7943. http://dx.doi.org/10.1364/AO.45.007938

[13] Caplan, J.D., Waxman, S., Nesto, R.W. and Muller, J.E. (2006) Near-Infrared Spectroscopy for the Detection of Vulnerable Coronary Artery Plaques. Journal of the American College of Cardiology, 47, C92-C96. http://dx.doi.org/10.1016/j.jacc.2005.12.045

[14] Gardner, C.M., Tan, H., Hull, E.L., Lisauskas, J.B., Sum, S.T., Meese, T.M., Jiang, C., Madden, S.P., Caplan, J.D., Burke, A.P., Virmani, R., Goldstein, J. and Muller, J.E. (2008) Detection of Lipid Core Coronary Plaques in Autopsy Specimens with a Novel Catheter-Based Near-Infrared Spectroscopy System. JACC: Cardiovascular Imaging, 1, 638648. http://dx.doi.org/10.1016/j.jcmg.2008.06.001

[15] Manolakis, D., Marden, D. and Shaw, G.A. (2003) Hyperspectral Image Processing for Automatic Target Detection Applications. Lincoln Laboratory Journal, 14, 79-116.

[16] Larsen, E.L.P., Randeberg, L.L., Olstad, E., Haugen, O.A., Aksnes, A. and Svaasand, L.O. (2011) Hyperspectral Imaging of Atherosclerotic Plaques in Vitro. Journal of Biomedical Optics, 16, Article ID: 026011. http://dx.doi.org/10.1117/1.3540657

[17] Moreno, P.R., Lodder, R.A., Purushothaman, K.R., Charash, W.E., O’Connor, W.N. and Muller, J.E. (2002) Detection of Lipid Pool, Thin Fibrous Cap, and Inflammatory Cells in Human Aortic Atherosclerotic Plaques by Near-Infrared Spectroscopy. Circulation, 105, 923-937. http://dx.doi.org/10.1161/hc0802.104291

[18] Wang, B., Karpiouk, A., Yeager, D., Amirian, J., Litovsky, S., Smalling, R. and Emelianov, S. (2012) Intravascular Photoacoustic Imaging of Lipid in Atherosclerotic Plaques in the Presence of Luminal Blood. Optics Letters, 37, 12441246. http://dx.doi.org/10.1364/OL.37.001244

[19] Troy, T.L. and Thennadi, S.N. (2001) Optical Properties of Human Skin in the Near Infrared Wavelength Range of 1000 to 2200 nm. Journal of Biomedical Optics, 6, 167-176. http://dx.doi.org/10.1117/1.1344191

[20] Burke, A.P., Farb, A., Malcom, G.T., Liang, Y., Smialek, J. and Virmani, R. (1997) Coronary Risk Factors and Plaque Morphology in Men with Coronary Disease Who Died Suddenly. New England Journal of Medicine, 336, 1276-1282. http://dx.doi.org/10.1056/NEJM199705013361802

[21] Sassaroli, A. and Fantini, S. (2004) Comment on the Modified Beer-Lambert Law for Scattering Media. Physics in Medicine and Biology, 49, N255-N257.

[22] Girouard, G., Bannari, A., El Harti, A. and Desrochers, A. (2004) Validated Spectral Angle Mapper Algorithm for Geological Mapping: Comparative Study between Quickbird and Landsat-TM. Proceedings of the 20th ISPRS Congress: Geo-Imagery Bridging Continents, Istanbul, 12-23 July 2004, 1099-1113.

[23] Nagao, R., Ishii, K., Kitayabu, A. and Awazu, K. (2013) Optimal Wavelengths of Atherosclerotic Plaque Observation in Near-Infrared Multispectral Imaging. Proceedings of SPIE, 8798, Article ID: 879808. http://dx.doi.org/10.1117/12.2032529

[24] Wang, J., Geng, Y., Guo, B., Klima, T., Lal, B.N., Willerson, J.T. and Casscells, W. (2002) Near-Infrared Spectroscopic Characterization of Human Advanced Atherosclerotic Plaques. Journal of the American College of Cardiology, 39, 1305-1313. http://dx.doi.org/10.1016/S0735-1097(02)01767-9

[25] He, J. and Karlsson, A. (2004) Light Scattering by Multiple Red Blood Cells. Journal of the Optical Society of America A, 21, 1953-1961. http://dx.doi.org/10.1364/JOSAA.21.001953

[26] Honda, N., Nanjo, T., Ishii, K. and Awazu K. (2012) Optical Properties Measurement of Laser Coagulated Tissues with Double Integrating Sphere and Inverse Monte Carlo Technique in the Wavelength Range from 350 to $2100 \mathrm{~nm}$. Proceedings of SPIE, 8221, Article ID: 82211F. http://dx.doi.org/10.1117/12.907704 
Scientific Research Publishing (SCIRP) is one of the largest Open Access journal publishers. It is currently publishing more than 200 open access, online, peer-reviewed journals covering a wide range of academic disciplines. SCIRP serves the worldwide academic communities and contributes to the progress and application of science with its publication.

Other selected journals from SCIRP are listed as below. Submit your manuscript to us via either submit@scirp.org or Online Submission Portal.
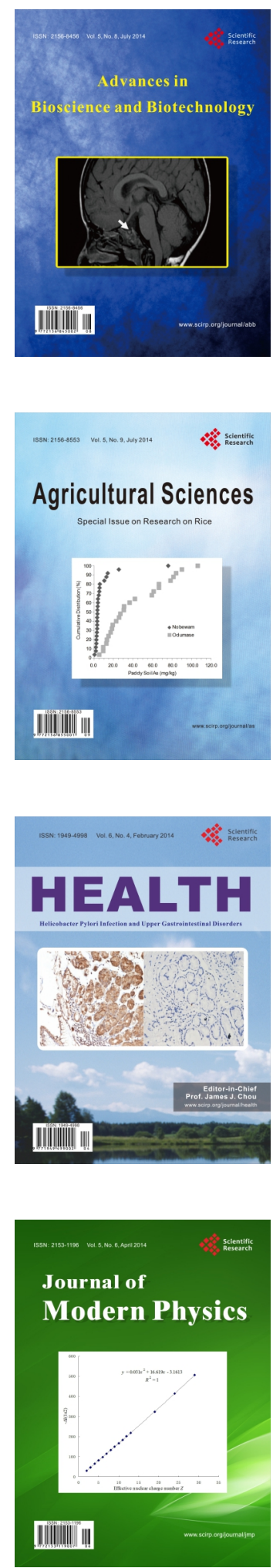
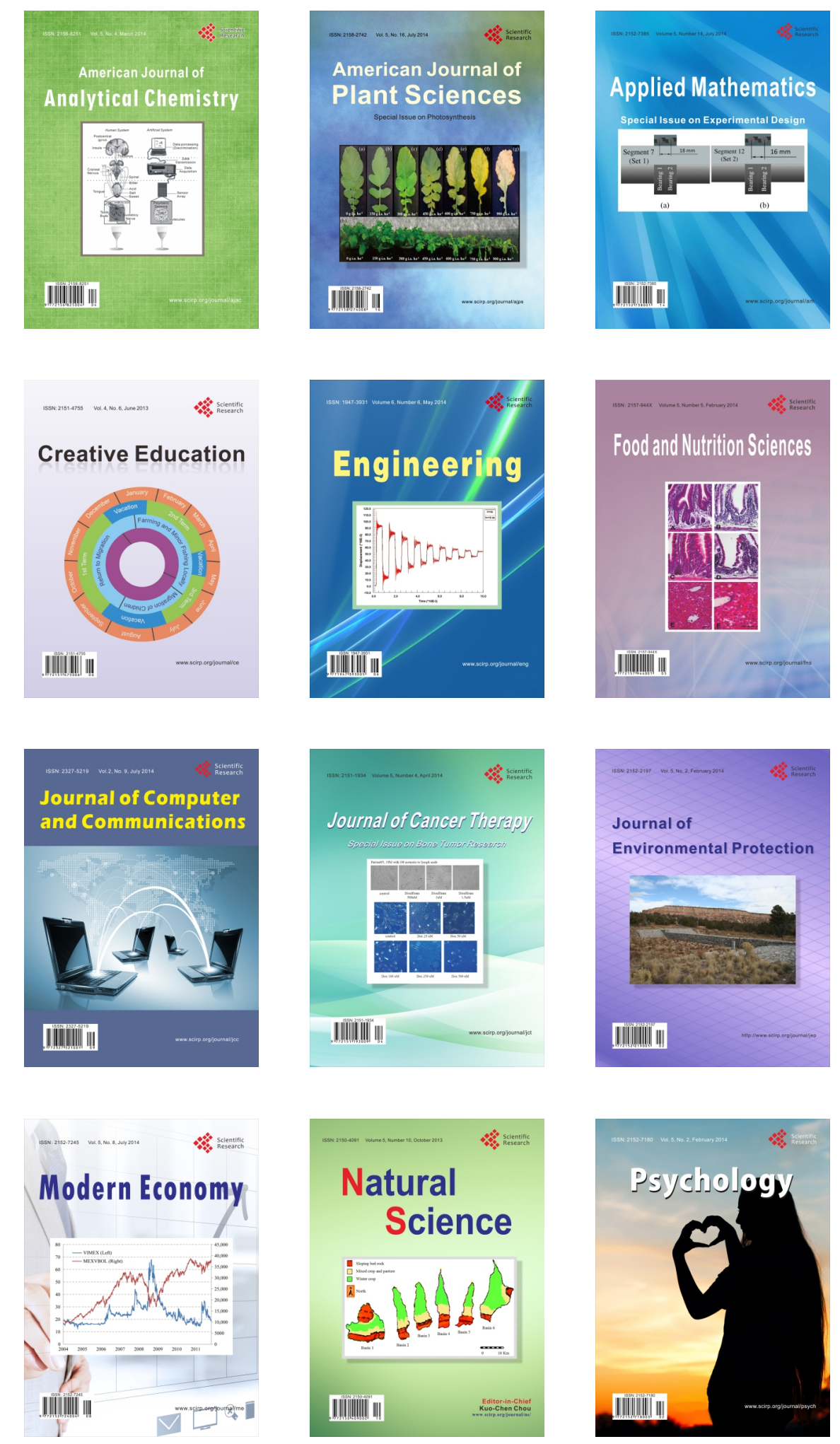